\title{
3 Research Square \\ Germinal Ovarian Tumors In Reproductive Age Women: Fertility-Sparing And Outcome
}

\section{Miriam Dellino ( $\nabla$ miriamdellino@hotmail.it )}

Gynecologic Oncology Unit, National Cancer Center, IRCCS Istituto Tumori “Giovanni Paolo II” Bari, Italy https://orcid.org/0000-0003-3522-4648

\section{Erica Silvestris}

Fondazione di Ricerca e Cura Giovanni Paolo II https://orcid.org/0000-0001-7415-5986

\section{Vera Loizzi}

Universita degli Studi di Bari Aldo Moro

\section{Angelo Paradiso}

Fondazione di Ricerca e Cura Giovanni Paolo II

\section{Gennaro Cormio}

Universita degli Studi di Bari Aldo Moro

\section{Research}

Keywords: ovarian neoplasms, malignant ovarian germ cell tumours, fertility-sparing-surgery, outcome, reproductive-age

Posted Date: February 3rd, 2020

DOI: https://doi.org/10.21203/rs.2.22468/v1

License: (c) (1) This work is licensed under a Creative Commons Attribution 4.0 International License. Read Full License

Version of Record: A version of this preprint was published at Medicine on September 25th, 2020. See the published version at https://doi.org/10.1097/MD.0000000000022146. 


\section{Abstract}

Purpose

MOGCTs (malignant ovarian germ cell tumours) is a rare tumour, which mainly affects patients in reproductive age. The aim of this study is evaluate the fertility and survival outcomes in young women with MOCGTs treated with fertility-sparing surgery (FFS).

Methods

From 2000 to 2018 twenty-eight patients with diagnosis of MOGCTs in reproductive age at the University of Bari were collected. Most received FFS and in patients treated conservatively, the reproductive outcome and survival were investigated. Data of patient demographics, clinical presentation, oncology markers dosage, staging, type of surgery histological examination, survival and reproductive outcome were collected from hospital and office charts. All informed consent was obtained from all patients

Results

Twenty-eight patients with diagnosis of MOGCTs were collected. The median age was 24 (range: 9-45). The majority of the patients had stage IIIC. Twenty-four woman received fertility-sparing surgery consisting in unilateral ovariectomy and omentectomy whereas only 4 women based on their stage (IIIC) received a radical surgery (hysterectomy with bilateral adnexectomy, lymphadenectomy and omentectomy). Our study shows that FFS in MOGCTs can produce good results both on reproductive outcomes and on survival. Indeed, in our group there was only one case of exitus as result of recurrence. On the other side, patients after FFS maintained normal ovarian function and $5 / 5$ women who have looked for pregnancy, obtained it spontaneously. The median follow-up was 90 moth (range 3-159).

Conclusion

Conservative surgery for MOGCTs should be considered for women in the reproductive age group who desire preservation of fertility.

\section{Introduction}

Germ cell tumors (OGCTs) represent the $20-25 \%$ of all ovarian neoplasms, whereas malignant ovarian germ cell tumors (MOGCTs) comprise only $5 \%$ of all ovarian cancers [1, 2].

MOGCTs show a peak prevalence in young women and adolescents. Approximately $60 \%$ of ovarian tumours are germ cell tumors in patients younger than 20 years and one third of these cases are malignant [3].

The MOGCTs include several histotypes, all deriving from primordial germ cells of the ovary and represent a heterogeneous group of tumours with variable biological behavior, clinical presentation and prognosis 
[4].

There is a variety of histologic types: dysgerminoma, immature teratoma, endodermal sinus tumor, choriocarcinoma, polyembryoma, and mixed MOGCTs [5].

These tumors differ from epithelial ovarian cancer (EOC) by incidence at an earlier age, for localization, almost unilateral (95\% of cases), for the high rate of growth, rare tendency to spread and finally for their good prognosis $[6,7]$. This is explained by the numerous of diagnoses at early stages and their high chemosensitivity [8].

Therefore, the treatment of this pathology in early stages requires only surgery while in presence of highrisk factors or advanced disease, after surgical treatment chemotherapy is highly recommended $[9,10]$.

The most used chemotherapeutic protocol is the combination of Bleomycin, Etoposide and Cisplatin (BEP) or Bleomycin, Vinblastine, Cisplatin (PVB) for $4-6$ cycles and this is based on histotype and stage [11].

Patients are followed up with abdominal-pelvic examination and ultrasound, complete blood count, and biochemistry profile every 2-3 months for the first 2 years, at semi-annual intervals up to year 5 and annual intervals thereafter. Chest X-ray is ordered at annual intervals or in case of clinical suspicion. Computed tomography of thorax and abdomen is performed every 6 months for the first 2 years and at annual intervals up to year 5 [12].

A variable long-term survival rate of $82 \%-100 \%$ is reported in the literature in the early stages and $75 \%$ in the advanced stages [12].Considering the frequent incidence of MOGCTs in young women and the high survival rate clinician should consider fertility-sparing surgery (FSS) [13]. The correct information about the risks of iatrogenic infertility and the strategies available to reduce the incidence of this effect (reproductive counselling) should be offered to young cancer patients immediately after diagnosis, subsequent stage of the disease and before the start of treatment [14]. The main techniques of fertility preservation in patients who need to undergo cancer treatments are: cryopreservation of embryos or eggs, cryopreservation of ovarian tissue, gonadic suppression with similar LHRH and conservative surgery. FSS is identified as the cornerstone of early-stage MOGCTs treatment. On the other hand, for the advanced stages, the possibility of performing an FSS in young patients who desire a pregnancy should be assessed in a personalized manner and after counselling with the patient [10]. Indeed, current literature presents reassuring data relating to favorable overall survival and reproductive outcome after FFS [11]. In this study we analyzed survival oucomes in women of childbearing age diagnosed with MOGCTs and treated with FFS. We also evaluated changes in the menstrual cycle and post-treatment pregnancies.

\section{Material And Methods}

From 2000 to 2018 all women in reproductive age with diagnosis of MOCGTs at the University of Bari were collected. 
Data of patient demographics, clinical presentation, oncology markers dosage, staging, type of surgery histological examination, survival and reproductive outcome were collected from hospital and office charts. All informed consent was obtained from all patients.

The evaluation of the disease stage has been performed using the FIGO classification [14] whereas the histopathological definition has been evaluated according to the classification of germ cell tumors of the ovary World Health Organization (WHO). [15].

A cytological analysis of the ascitic fluid or the peritoneal washing and an intra-operative histological examination was performed was performed in all cases. In addition, all patients presented an extemporaneous of germ cell tumour subsequently confirmed at the definitive histological examination.

The "maximum" debulking was defined as a tumour residue $=0$ after primary or recurrent surgery, "optimal" in the case of a $1 \mathrm{~cm}$ tumour residue and "not optimal"> $1 \mathrm{~cm}$.

Disease-free survival (DFS) was defined as the period between diagnosis and recurrence, whereas overall survival, (OS) was identified as the period between diagnosis and the time of death or last follow up [16].

Adjuvant BEP or PVB (average of 4 cycles every 3 weeks) was indicated for patients with IC or higher disease, immature teratoma or high-grade tumors, residual disease after cytoreductive surgery. Patient are followed up with abdominal and pelvic examination and ultrasound, blood count and tumor marker dosage every 2-3 months, for the first 2 years, at semi-annual intervals up to year 5 and at annual intervals thereafter. Computed tomography of thorax and abdomen is performed every year for the first 5 years. Chest $\mathrm{X}$-ray was indicated at annual intervals for the first two years.

\section{Results}

Twenty-eight patients with diagnosis of MOGCTs were collected. The median age was 24 (range: 9-45). The majority of the patients had stage IIIC. Most received fertility-sparing surgery consisting in unilateral ovariectomy and omentectomy whereas only 4 women based on their stage (IIIC) received a radical surgery (hysterectomy with bilateral adnexectomy, lymphadenectomy and omentectomy) The median follow-up was 90 moth (range 3-159).(Table I). The onset of the disease was pain in 18 (64\%), abdominal distension in $26(26 \%)$, ascites in 2 (7\%), dyspareunia in $3(10 \%)$, weight gain $2(7 \%)$, vaginal bleeding 1 $(3,5 \%)$ and symptomless in 3 women (10\%). The average diameter of the neoplasms was $9.2 \mathrm{~cm}$ (range $5-20)$. It was also recorded an increase in the following tumor markers CA-125 in $3(10,7 \%), \beta$-hcg in 6 $(21,4 \%)$ a-feto-protein (AFP) in 11 (39\%), CA 19.9 in 2 (7\%) and CA-15.3 in 1 patient (3\%). None of our patients showed an increase of the CEA. Tumor histology included $4(14 \%)$ teratomas, 11 dysgerminomas (39\%), 3 (10\%) endodermal sinus tumor, mixed MOCGTs 10 tumors (35\%). Ten women had I A (35\%), 5 presented stage I C (32\%), 5 stage II A (18\%) and 4 IIIC (14\%) stage disease. Therefore, a total of 18 patients were treated with adjuvant therapy: 16 with BEP and 2 with PVC. The chemotherapeutic regimen was administered for 4 cycles every 3 weeks (Table 1). Three women (12\%) treated with FFS with an histology different from dysgerminoma had a recurrence 6 years after treatment, therefore a completion 
of surgery was performed. Of the 28 women, two women expired: one with a diagnosis of endodermal sinus tumor dead for her disease progression despite radical surgery and chemotherapy and another dead for her severe fatal toxicity after the first cycle of PVB chemotherapy. Fertility preservation techniques were used in 8 patients by performing GnRH analogues during chemotherapy and in two cases through cryopreservation of ovarian tissue and cryopreservation of oocytes upon commencement of treatment, respectively. Later in these last two cases both patients had spontaneous pregnancy without having to resort to thawing. Of the 28 patients of child-bearing age diagnosed with MOCGTs excluding the 4 patients who had performed hysterectomy after diagnosis, 3 after recurrence, 1 patient with pure gonadal dysgenesis (Swyer syndrome -karyotype $46 \mathrm{XY}$ ) and 1 death after chemotoxicity, we investigated on the regularity of the post-treatment menstrual cycle and reproductive status. Among these nineteen women, 15 (78\%) reported regular menstrual cycles during and after chemotherapy; on the other hand the remaining $4(21 \%)$ presented amenorrhea during chemotherapy but referred regular cycles after the end of treatment. Regarding the reproductive outcome, 4 patients had a pregnancy before the disease without attempting further conception, 11 patients (average age 32 years) declared that they were not currently interested in childbearing, 1 women had a spontaneous abortion (SAB) at 7 weeks, 1 had a voluntary pregnancy interruption (IVP) at 22 weeks following a diagnosis of multiple fetal malformations and the remaining 5 reported having achieved pregnancy through spontaneous conception and with vaginal delivery. Of these 5 women the median time to achieve a pregnancy was 8 years from surgery (range $3-15$ years) and 4 of them had a combination of BEP $+\mathrm{GnRH}$ analogue whereas 1 only chemotherapy after surgery. (Table 2). 
Table 1

Patient Characteristics and Treatment Data

\begin{tabular}{|c|c|}
\hline a. Characteristic & Data \\
\hline No. of patients & 28 \\
\hline Median age (yr) (range) & $24(9-45)$ \\
\hline Median gravidity (range) & $1(0-6)$ \\
\hline Median age at menarche (yr) (range) & $14(11-17)$ \\
\hline Median follow-up & $90(3-159)$ \\
\hline b. Clinical presentation & Data (\%) \\
\hline Pain or pressure & $18(64 \%)$ \\
\hline Symptomless & $3(10,7 \%)$ \\
\hline Abdominal distention & $26(92 \%)$ \\
\hline Ascites & $2(7,1 \%)$ \\
\hline Mass diameter (range) & $9,2 \mathrm{~cm}(5-20)$ \\
\hline Dyspareunia & $3(10 \%)$ \\
\hline Weight gain & $2(7,1 \%)$ \\
\hline Vaginal bleeding & $1(3,5 \%)$ \\
\hline c. Surgical procedure & Data (\%) \\
\hline Unilateral oophorectomy & $9(32 \%)$ \\
\hline Unilateral oophorectomy, omentectomy, lymphadenectomy & $13(46,4)$ \\
\hline Bilateral oophorectomy & $1(3,5 \%)$ \\
\hline Hysterectomy with unilateral oophorectomy, lymphadenectomy, omentectomy & $1(3,5 \%)$ \\
\hline Hysterectomy with bilateral oophorectomy,lymphadenectomy, omentectomy & $3(10,7 \%)$ \\
\hline d. Stage & Data(\%) \\
\hline IA & $10(35 \%)$ \\
\hline IC & $9(32,1 \%)$ \\
\hline IIA & $5(17,8 \%)$ \\
\hline IIIC & $4(14,2 \%)$ \\
\hline
\end{tabular}




\begin{tabular}{|ll|}
\hline a. Characteristic & Data \\
\hline e. Cell Type & Data (\%) \\
\hline Teratomas & $4(14,2 \%)$ \\
\hline Dysgerminomas & $11(39 \%)$ \\
\hline Endodermal sinus tumor & $3(10,7 \%)$ \\
\hline Mixed MOGCTs & $10(35 \%)$ \\
\hline f. Markers & Data \\
\hline CA-125 & $3(10,7 \%)$ \\
\hline CA 19.9 & $2(7,1 \%)$ \\
\hline CA 15.3 & $1(3,5 \%)$ \\
\hline a-FP & $11(39,2 \%)$ \\
\hline$\beta$-hcg & $6(21,4 \%)$ \\
\hline CEA & 0 \\
\hline$\beta$-hcg + a-FP & $3(10,7 \%)$ \\
\hline Ca-125+a-FP & $2(7,14 \%)$ \\
\hline
\end{tabular}


Table 2

Pregnancy Outcome

\begin{tabular}{|c|c|c|c|c|c|c|}
\hline $\begin{array}{l}\text { Case } \\
\text { no. }\end{array}$ & Stage & Histology & Procedure & CHT & $\begin{array}{l}\text { Pregnancy } \\
\text { event }\end{array}$ & status \\
\hline 1 & IA & Mixed MOGCTs & U.A.+Omentectomy & NO & $\begin{array}{l}\text { 2 Term } \\
\text { SVD }\end{array}$ & NED \\
\hline 2 & IC & $\begin{array}{l}\text { Endodermal sinus } \\
\text { tumour }\end{array}$ & U.A.+Omentectomy & BEPx 5 & $\begin{array}{l}1 \text { Term } \\
\text { SVD }\end{array}$ & NED * \\
\hline 3 & IC & Teratomas & U.A.+Omentectomy & $\begin{array}{l}\text { BEPx } \\
5\end{array}$ & $\begin{array}{l}2 \text { Term } \\
\text { SVD }\end{array}$ & NED \\
\hline 4 & III C & Mixed MOGCTs & $\begin{array}{l}\text { U.A.+Omentectomy + } \\
\text { multiple biopsies }\end{array}$ & $\begin{array}{l}\text { BEP X } \\
5\end{array}$ & $\begin{array}{l}1 \text { Term } \\
\text { SVD }\end{array}$ & NED \\
\hline 5 & III C & Dysgerminomas & $\begin{array}{l}\text { U.A.+Omentectomy + } \\
\text { multiple biopsies }\end{array}$ & $\begin{array}{l}\text { BEP X } \\
5\end{array}$ & $\begin{array}{l}2 \text { Term } \\
\text { SVD }\end{array}$ & NED \\
\hline 6 & IIIC & Dysgerminomas & $\begin{array}{l}\text { U.A.+Omentectomy + } \\
\text { multiple biopsies }\end{array}$ & $\begin{array}{l}\text { BEP X } \\
5\end{array}$ & $1 \mathrm{SAB}$ & NED \\
\hline 7 & IIIC & Mixed MOGCTs & $\begin{array}{l}\text { U.A.+Omentectomy + } \\
\text { multiple biopsies }\end{array}$ & $\begin{array}{l}\text { BEP X } \\
5\end{array}$ & 1 IVP & NED \\
\hline \multicolumn{7}{|c|}{$\begin{array}{l}\text { UA = unilateral adnexectomy, SAB = spontaneous abortion, SVD = spontaneous vaginal delivery, NED } \\
\text { = no evidence of disease, BEP = Bleomycin, Etoposide and Cisplatin, IVP: voluntary interruption of } \\
\text { pregnancy }\end{array}$} \\
\hline \multicolumn{7}{|c|}{ *DDI: patient NED deceased regardless of illness (suicide) } \\
\hline
\end{tabular}

\section{Discussion}

About $60 \%$ of OGCTs are diagnosed in patients under the age of 20 and one third of these are malignant [16]. Most of these tumors present a favorable prognosis due to early diagnosis, unilateral localization, rare metastatization [17] and high chemo-sensitivity [18].

Therefore, FSS in MOCGT in the early stages is considered the therapeutic standard in women who want to maintain their reproductive function $[19,20]$.

Several studies report reassuring data even in advanced MOGCTs, both on overall survival $(87.9 \%$ at 5 years) and on the absence of alterations of the menstrual cycle and reproductive function [21].

In literature, the increase in AFP levels and a different histology from the dysgerminoma has been correlated to a greater incidence of recurrences. Therefore, in these cases a more extensive surgical treatment and a greater number of chemotherapy cycles could be indicated, after individualized evaluation of the risk factors[22-24] This is also reflected in terms of OS which in the literature is reported to be equal to $97 \%$ in cases of dysgerminoma while in non-germinomas is $60 \%(p<0.001)$ [25]. 
Actually, in our experience all cases of recurrence recorded showed a histology different from the dysgerminoma and high dosage of AFP in the only case evolved in exitus for her disease. Surgical treatment of advanced states must be supplemented with chemotherapy whose effects on fertility have been widely discussed in literature. Solheim et al. compared patients who received 3 cycles of platinumbased chemotherapy with those who received more than three cycles. In the latter group the rate of infertility was significantly higher $(p=0.040)[26-28]$. Some authors found a reduction of primordial follicles, stromal fibrosis following chemotherapy, with a parallel increase in gonadotropins and reduced levels of estrogen. $[29,30]$.These effects seem to be closely related to the type of drugs, dose and chemotherapy duration. [31]

In our study there is no evidence on any reproductive outcome reduction following multiple chemotherapy cycles. Similar data are reported in several papers that showed that PEB versus PVC chemotherapy for MOCGTs does not appear to affect reproduction or menstrual cycle which normalized within 6 months in $90 \%$ of cases [32-34].Similarly, we reported that $78 \%$ of the patients had regular menstrual cycles during and after chemotherapy, on the other side $22 \%$ patients presented amenorrhea during chemotherapy but had regular cycles 5 months after treatment.

As regards of fertility preservation techniques, treatment with GNRH analogues concomitant with adjuvant chemotherapy was proposed in 8 of the 18 patients and 4 of these had spontaneous pregnancies. In one case the chemotherapy was performed alone. Indeed, recent studies support that chemotherapy regimens used for these neoplasms do not show particular toxicity, therefore the association with GNRH analogues would not change the effects on fertility compared to the execution of the isolated therapy $[35,36]$.

Although in subjects with ovarian dysfunction at the starting stage, the association of the GnRH analogue may be indicated. Pre-treatment anti-Mullerian-hormone (AMH) serum levels and age of each patient, appear to be reliable predictive factors of ovarian activity recovery after treatment $[13,36]$.

Similarly, literature reports that AMH dosage and the fertility evaluation pre-treatment can help in the identification of patients with deficient ovarian reserve and who could benefit from a fertility preservation technique [37].

In this study, there were a very small percentage of pregnancy failure: 1 had SAB and 1 had IVP; these percentages are typically reported in a general population [38], therefore it is difficult to demonstrate a relationship [39]. The literature on the possible dangerous effects of cancer treatments on pregnancy did not show an increased risk of genetic or other defects in births of women previously receiving treatment antineoplastic [40]. Nevertheless, in these women, considering limited cases studied, it would be advisable monitoring pregnancy more strictly [14]. Indeed, the limitations of this study are represented by the limited number of cases, and retrospective analysis

\section{Conclusions}


MOGCTs are rare tumors, which mainly affects patients in reproductive age [13]. The increase of therapeutic rates has moved the attention of recent studies on variations of the menstrual cycle and reproductive outcome in patients after cure. Several studies report reassuring data relating to FFS treatment of MOCGTs in early stages, therefore in these cases conservative surgery is now consolidated as a safe procedure. Moreover, for MOGCTs in advanced stages treated conservatively, literature reports a non-compromised DFS and OS [7]. In this case personalized follow-up should be proposed in order to consider the risk factors, timing and nature of the relapse [4].Furthermore, our study shows that FFS in advanced stages can produce good results both on reproductive outcomes and on survival. Indeed, in our group there was only one case of exitus as result of recurrence. On the other side, patients after FFS maintained normal ovarian function and $5 / 5$ women who have looked for pregnancy, obtained it spontaneously. Also literature studies performed on a larger population report that patients with MOGCTs undergoing FST had reassuringly high conception rates and low premature ovarian failure rates; however, in pre-treatment counselling, the risks of this approach in such young population should be discussed[41].Nevertheless, considering the rarity of advanced stage MOGCTs (20-30\%) [17] and the few cases treated conservatively, safety of FFS is accepted but not fully clinically supported yet [42].

Therefore, conservative surgery for MOGCTs in advanced stages needs greater number of cases and meta-analysis in order to obtain a higher grade of recommendation [21] but currently may represent a therapeutic option in patients available for extended follow-up and after subscribing to informing consent [43].

\section{Declarations}

\section{Ethical Approval and consent to partecipate}

There is no formal approval of the Ethics Committee, but the procedures were carried out in accordance with the Helsinki Declaration, as revised in 2013.

Informed consent was obtained for the patient through a dedicated form containing study desing.

\section{Consent For Publication}

Written informed consent for the anonymous publication of information relating to the disease is regularly obtained,from all individual participants included in the study,during the medical interview with the patient prior to the surgical or chemotherapy treatment.

\section{Availability of data and materials}

The datasets used during the current study are available from the corresponding author on reasonable request.

\section{Competing interests}

The authors declare that they have no competng interests 


\section{Funding}

This work has been supported by a grant $(5 \times 1000)$ from the IRCCS Istituto Tumori "Giovanni Paolo II" Bari, Italy (number 332/2019) in the context of a scientific program exploring the ovarian stem cell development to prevent infertility in oncological patients. The APC will be funded by IRCCS Istituto Tumori “Giovanni Paolo II" Bari, Italy.

\section{Authors Contribution}

MD: (Corresponding authors) She has made substantial contributions to the conception of the work and she approved the submitted version and she agreed both to be personally accountable for the author's own contributions and to ensure that questions related to the accuracy or integrity of any part of the work, even ones in which she was not personally involved, are appropriately investigated, resolved, and the resolution documented in the literature.

ES: She has made substantial contributions to design of the work and approved the submitted version and is agreed both to be personally accountable for the author's own contributions and to ensure that questions related to the accuracy or integrity of any part of the work, even ones in which she was not personally involved, are appropriately investigated, resolved, and the resolution documented in the literature.

VL: She has made substantial contributions to the acquisition, analysis of data and she approved the submitted version and she agreed both to be personally accountable for the author's own contributions and to ensure that questions related to the accuracy or integrity of any part of the work, even ones in which the author was not personally involved, are appropriately investigated, resolved, and the resolution documented in the literature.

AP: He has made substantial contributions to draft the work and substantively revise it. He has also approved the submitted version and he agreed both to be personally accountable for the author's own contributions and to ensure that questions related to the accuracy or integrity of any part of the work, even ones in which he was not personally involved, are appropriately investigated, resolved, and the resolution documented in the literature

GC: He has made substantial contributions to draft the work and substantively revise it. He has also approved the submitted version and he agreed both to be personally accountable for the author's own contributions and to ensure that questions related to the accuracy or integrity of any part of the work, even ones in which he was not personally involved, are appropriately investigated, resolved, and the resolution documented in the literature

\section{Acknowledgments}

This research project has been supported in part by the Apulian Regional Project "Medicina di precisione". 


\section{References}

1)Mangili G, Sigismondi $C$, Gadducci A, Cormio G, Scollo P, Tateo $S$, et al.Outcome and risk factors for recurrence in malignant ovarian germ cell tumors: a MITO-9 retrospective study.Int J Gynecol Cancer.2011; $21: 1414-21$.

2)Pectasides D, Pectasides E, Kassanos D.Germ cell tumors of the ovary. Cancer Treat Rev. 2008;34:42741.

3)Goyal LD, Kaur B, Badyal RK. Malignant Mixed Germ Cell Tumors of the Ovary: A Series of Rare Cases.J Reprod Infertil. 2019;20:231-236.

4)Mangili G, Sigismondi C, Lorusso D, Cormio G, Candiani M, Scarfone $G$ et al .The role of staging and adjuvant chemotherapy in stage I malignant ovarian germ cell tumors (MOGTs): the MITO-9 study.Annals of Oncology. 2017; 28: 333-338.

5)Anita AN, Rushdan MN .Reproductive function after treatment of ovarian germ cell malignancy. Med J Malaysia. 2012;67:71-6.

6)Low JJH, Ilancheran A, Ng JS .Malignant ovarian germ-cell tumours. Best Pract Res Clin Obstet Gynaecol. 2012; 26:347-55.

7)Park JY, Kim DY, Suh DS, Kim JH, Kim YM, Kim YT,et al.Analysis of outcomes and prognostic factors after fertility-sparing surgery in malignant ovarian germ cell tumors. Gynecol Oncol.2017;145:513-8.

8) Lambertini M, Dellepiane C, Viglietti G, Del Mastro L.Pharmacotherapy to protect ovarian function and fertility during cancer treatment. Expert Opin Pharmacother.2017;18(8):739-742.

9)Ray-Coquard I, Morice P, Lorusso D, Prat J, Oaknin A, Pautier P, Colombo N; ESMO Guidelines Committee.Non-epithelial ovarian cancer: ESMO Clinical Practice Guidelines for diagnosis, treatment and follow-up. Ann Oncol.2018;29 .doi: 10.1093/annonc/mdy001.

10) Brown J, Friedlander M, Backes FJ, Harter $P$, O'Connor DM, de la Motte Rouge T,et al.Gynecologic Cancer Intergroup (GCIG) consensus review for ovarian germ cell tumors.Int J Gynecol Cancer.2014;48-54

11) Kang H, Kim TJ, Kim WY, Choi CH, Lee JW, Kim BG, Bae DS. Outcome and reproductive function after cumulative high-dose combination chemotherapy with bleomycin, etoposide and cisplatin (BEP) for patients with ovarian endodermal sinus tumor. Gynecol Oncol.2008;111:106-10.

12) Smith HO, Berwick $M$, Verschraegen $C F$, Wiggins $C$, Lansing $L$, Muller $C Y$, et al. Incidence and survival rates for female malignant germ cell tumors. Obstet Gynecol.2006;107:1075-85.

13) Turkmen O, Karalok A, Basaran D, Kimyon GC, Tasci T, Ureyen I ,et al. Fertility-Sparing Surgery Should Be the Standard Treatment in Patients with Malignant Ovarian Germ Cell Tumors. J Adolesc Young Adult 
14) Hohmann C, Borgmann-Staudt A, Rendtorff R, Reinmuth $S$, Holzhausen $S$, Willich SN, et al. Patient counselling on the risk of infertility and its impact on childhood cancer survivors: results from a national survey. J Psychosoc Oncol.2011;29:274-85.

15) Prat J.FIGO Committee on Gynecologic Oncology. Staging classification for cancer of the ovary, fallopian tube, and peritoneum. Int J Gynaecol Obstet.2014;124:1-5.

16) Kaku T, Ogawa S, Kawano Y, Ohishi Y, Kobayashi H, Hirakawa T,et al. Histological classification of ovarian cancer. Med Electron Microsc.2003;36:9-17.

17) Lo Presti A, Ruvolo G, Gancitano RA, Cittadini E. Ovarian function following radiation and chemotherapy for cancer. Eur J Obstet Gynecol Reprod Biol. 2004;1:33-40.

18) Smith $H O$, Berwick $M$, Verschraegen $C F$, Wiggins $C$, Lansing $L$, Muller $C Y$,et al. Incidence and survival rates for female malignant germ cell tumors. Obstet Gynecol. 2006;107:1075-85.

19) Liu Q, Ding $X$, Yang J, Cao D, Shen $K$, Lang J,et al. The significance of comprehensive staging surgery in malignant ovarian germ cell tumors. Gynecol Oncol. 2013;131:551-4.

20) Palenzuela G, Martin E, Meunier A, Beuzeboc P, Laurence V, Orbach D, et al. Comprehensive staging allows for excellent outcome in patients with localized malignant germ cell tumor of the ovary. Ann Surg.2008;248:836-41.

21) Nasioudis D, Frey MK, Chapman-Davis E, Caputo TA, Holcomb K. Fertility-preserving surgery for advanced stage ovarian germ cell tumors. Gynecol Oncol.2017;147:493-496.

22) Oktay K, Harvey BE, Loren AW. Fertility Preservation in Patients With Cancer: ASCO Clinical Practice Guideline Update Summary. J Oncol Pract.2018;14(6):381-385.

23) Elbrashy AA, Kamal A, Fahim MI. Methods of Treatment and Outcome for Ovarian Germ Cell Tumors. Indian J Surg Oncol.2019;10:640-642.

24) Chan JK, Tewari KS, Waller S, Cheung MK, Shin JY, Osann K, et al. The influence of conservative surgical practices for malignant ovarian germ cell tumors. J Surg Oncol. 2008;98:111-6.

25) Cicin I, Eralp Y, Saip P, Ayan I, Kebudi R, lyibozkurt C,et al.Malignant ovarian germ cell tumors: a singleinstitution experience. Am J Clin Oncol.2009;32:191-6. 26) Solheim O, Tropé CG, Rokkones E, Kærn J, Paulsen T, Salvesen HB, et al. Fertility and gonadal function after adjuvant therapy in women diagnosed with a malignant ovarian germ cell tumor (MOGCT) during the "cisplatin era". Gynecol Oncol. 2015;136(2):224-9. 
27) Tomao F, Di Pinto A, Sassu CM, Bardhi E, Di Donato V, Muzii L, et al. Fertility preservation in ovarian tumours.Ecancermedicalscience. 2018;12:885.

28) Lee SJ, Schover LR, Partridge AH, Patrizio P, Wallace WH, Hagerty K,et al. American Society of Clinical Oncology. American Society of Clinical Oncology recommendations on fertility preservation in cancer patients. J Clin Oncol.2006;24(18):2917-31.

29) Del-Pozo-Lérida S, Salvador $C$, Martínez-Soler F, Tortosa A, Perucho M, Giménez-Bonafé P. Preservation of fertility in patients with cancer (Review). Oncol Rep. 2019;41(5):2607-2614.

30) Lo Presti A, Ruvolo G, Gancitano RA, Cittadini E. Ovarian function following radiation and chemotherapy for cancer. Eur J Obstet Gynecol Reprod Biol. 2004;113:33-40.

31) Chen Y, Luo Y, Han C, Tian W, Yang W, Wang Y, et al. Ovarian dysgerminoma in pregnancy: A case report and literature review. Cancer Biol Ther. 2018;19:649-658.

32) Zhang R, Sun YC, Zhang GY, Wu LY, Zuo J. Treatment of malignant ovarian germ cell tumors and preservation of fertility.Eur J Gynaecol Oncol.2012;33:489-92.

33) Zanetta G, Bonazzi C, Cantù M, Binidagger S, Locatelli A, Bratina G, et al.Survival and reproductive function after treatment of malignant germ cell ovarian tumors. J Clin Oncol.2001;19:1015-20.

34) Gershenson DM, Miller AM, Champion VL, Monahan PO, Zhao Q, Cella D,et al. Gynecologic Oncology Group. Reproductive and sexual function after platinum-based chemotherapy in long-term ovarian germ cell tumor survivors: a Gynecologic Oncology Group Study. J Clin Oncol. 2007;25:2792-7

35) Yang B, Yu Y, Chen J, Zhang Y, Yin Y, Yu N, et al. Possibility of women treated with fertility-sparing surgery for non-epithelial ovarian tumors to safely and successfully become pregnant-a Chinese retrospective cohort study among 148 cases. Front Med. 2018;12(5):509-517. 29218679.

36) Johansen G, Dahm-Kähler P, Staf C, Flöter Rådestad A, Rodriguez-Wallberg KA. Fertility-sparing surgery for treatment of non-epithelial ovarian cancer: Oncological and reproductive outcomes in a prospective nationwide population-based cohort study. Gynecol Oncol. 2019;155(2):287-293.

37) Ottolina J, Mangili G, Sigismondi C, Vanni VS, Viganò P, Candiani M. Reproductive function assessment after surgery plus chemotherapy for germ cell ovarian tumors (MOGCT): novel clues deriving from the field of fertility preservation.Gynecol Endocrinol.2014;30:778-80.

38)Levi Setti PE, Porcu E, Patrizio P, Vigiliano V, de Luca R, d'Aloja P, et al. Human oocyte cryopreservation with slow freezing versus vitrification. Results from the National Italian Registry data, 2007-2011.Fertil Steril. 2014;102:90-95.

39) Low JJ, Perrin LC, Crandon AJ, Hacker NF. Conservative surgery to preserve ovarian function in patients with malignant ovarian germ cell tumors. A review of74 cases. Cancer. 2000;89:391-8. 
40) Boyle KE, Vlahos N, Jarow JP. Assisted reproductive technology in the new millennium: part II. Urology. 2004;63:217-24.

41) Ceppi L, Galli F, Lamanna M, Magni S, Dell'Orto F, Verri D, et al. Ovarian function, fertility, and menopause occurrence after fertility-sparing

surgery and chemotherapy for ovarian neoplasms. Gynecol Oncol.2019;152:346-352.

42) Ghaemmaghami F, Hasanzadeh $M$, Karimi Zarchi M, Fallahi A. Nondysgerminomatous ovarian tumors: clinical characteristics, treatment, and outcome. A case-controlled study. Int J Surg. 2008;6:382-6.

43) Ghalleb M, Bouzaiene H, Slim S, Hadiji A, Hechiche M, Ben Hassouna J,et al. Fertility-sparing surgery in advanced stage malignant ovarian germ cell tumor: a case report. J Med Case Rep. 2017;11:350. 